\title{
Barriers to reading in higher education: Rethinking reading support
}

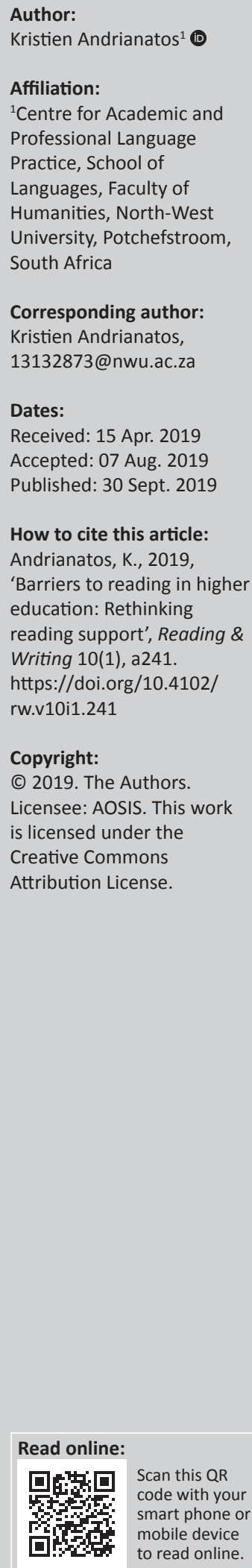

Background: Reading is a functional academic literacy ability needed by students in higher education. In the South African context, inadequate reading ability is one of the reasons for high undergraduate attrition rates. It seems that role players within this sector are of the opinion that students have reading 'problems' that need to be 'fixed', often by generic reading courses. This article differs from the perception of reading 'problems', as reading is viewed from a lifespan developmental perspective. According to this perspective undergraduate students do not have reading 'problems' but experience reading barriers hindering their reading development and in effect their academic literacy.

Objectives: This study aimed to uncover some of these barriers by means of an empirical study conducted at the North-West University (NWU).

Method: The setting of this study was the Potchefstroom campus of the NWU. A qualitative methodology was chosen whereby 14 individual interviews and 7 focus group interviews were used. The purpose of these interviews was to better understand lecturers' and students' perceptions about the variables of the reading process, namely the reading ability of the reader, the text to be read, the task, and the socio-cultural context.

Results: Lecturers and students perceived a number of reading barriers within each variable, namely students' non-compliance and lack of abilities, elements of the textbook and availability of lecturer notes, the format of the task, throughput pressures, and lecturers' assumptions.

Conclusion: Knowledge of these barriers and knowledge of the interconnectedness of the reading process could enable role players to collaboratively rethink undergraduate reading support, in which the lecturer has a crucial role to play.

Keywords: Academic literacy; higher education; undergraduate students; reading; reading comprehension; reading development; reading barriers; tasks; textbooks; socio-cultural context; lecturers.

\section{Introduction}

It has been known for a number of years that many learners who pass through the education system exit without being able to comprehend what they read (Berndt, Petzer \& Wayland 2014; Pretorius 2002; Van Dyk, Van der Poel \& Van der Slik 2013). For the fortunate who enter higher education, understanding an academic text seems to be a challenging task (Bharuthram 2012; Boakye, Sommerville \& Debusho 2014; MacMillan 2014; Pretorius 2005; Schoenbach, Greenleaf \& Murphy 2012; Taraban, Rynearson \& Kerr 2000). As more and more students are gaining access to higher education (Wingate 2007:392), higher education institutions experience pressure to help an increasing number of underprepared students to succeed. Understanding what you read is integral in this success. Indeed, reading is one of the functional academic literacy abilities (Butler 2013; Pretorius 2005) and research indicates that inadequate reading ability is partly to blame for students' academic failure and the high attrition rates of undergraduate students in South Africa (McLoughlin \& Dwolatzky 2014; Scott, Yeld \& Hendry 2007; Styan 2014). As a result, many institutions in South Africa offer academic support to their students, which usually includes a reading component of some sort.

There is limited research available on reading support provided to undergraduate students. Notably, research on undergraduate reading is not at all prevalent (Alexander 2005:415). A possible reason for this is that at university reading per se is not assessed, only the outputs of reading in the form of assessments (Bharuthram 2012; Nel, Dreyer \& Klopper 2004; Pretorius 2002:170, 2005:812). If one takes into account that in higher education, reading is learning (Taraban et al. 2000:284), I am of the opinion that role players need to know more about undergraduate reading 
and specifically the reasons why students struggle to understand what they read. In an attempt to address this lacuna, the aim of this article is to report on an empirical study conducted at the Potchefstroom campus of the NorthWest University (NWU) that investigated reading barriers ${ }^{1}$ that first-year students and their lecturers perceive. I am of the opinion that knowledge of these barriers could prove insightful to role players with regard to undergraduate reading support.

\section{Research relating to reading support}

Hallet (2013:519) states that literature related to learnerfocused support views academic literacy as the mastery of a set of skills, namely reading, writing, speaking, listening and thinking or reasoning. Along similar lines Butler (2013:75) finds that conversations about reading at university are often based on an approach that advocates for the acquisition of these skills. I would also argue that the reading support currently provided at the NWU, where the study took place, falls within this approach. Students are offered a generic reading course aimed at improving their reading skills as part of achieving academic literacy.

Research shows that institutions choose this approach for a number of reasons. Firstly, it means that the lecturer teaching disciplinary content is exonerated. This approach suits lecturers, as they do not regard themselves to be responsible for 'teaching reading' (Howard et al. 2018:193; Niven 2005:786; Wingate 2007:396). Jacobs (2007:60) adds that this responsibility is thus shifted to the shoulders of academic literacy practitioners. Secondly, generic reading support courses are convenient in terms of 'cost-effectiveness and administrative effort' (Wingate 2007:393). Such courses only require a certain number of practitioners to cater for students of all disciplines. Thirdly, it seems that universities offer such generic support 'both as a politically astute form of marketing and as an attempt to combat undergraduate attrition rates' (Hallet 2013:519).

According to Archer (2006:450), defining academic literacy as a neutral set of skills that can be taught and acquired has increasingly become contested in this research field. Research has therefore started to note the ineffectiveness of the type of generic academic literacy skills courses of which reading courses typically form a part. This generic approach suggests that the 'problems' are situated within the students themselves and they are held responsible for their 'shortcomings' (Hallet 2013; Wingate 2007). Wingate (2007) and Hallet (2013) both further explain that generic skills courses are divided into reading and discipline-specific academic literacy. Butler (2013:78) confirms this division, adding that a limitation of generic support is that 'irrelevant content not grounded in the discipline is demotivating students struggle to read, as it figuratively stands in the way of students' reading development. to students and the generic skills are not transferred to the disciplines'.

A fellow literacy lecturer, frustrated with some academics' short-sighted view on reading issues at the university, conjured a metaphor to explain this dilemma. My colleague believes that the perception among lecturers is that students who struggle to understand what they read have a so-called 'reading illness'. These academics do not consider themselves qualified to make the right diagnosis and they think that they do not have the right cure. Therefore, they hope that struggling students will find their way to the academic literacy department or the student or reading support office. Academic literacy practitioners or the support office are viewed as the doctors who have to figure out what is wrong with the students' reading so that they can give them the right cure.

I would argue, along with Alexander (2005), that reading needs to be viewed from another perspective in order to open up alternative approaches to reading support. Alexander proposes a lifespan developmental perspective on reading. According to this perspective, 'reading development is a lifelong journey that unfolds in multiple stages' (Alexander 2005:413). She states that readers never come to the point where their reading is perfect. All readers continue to encounter problems with written language in every stage of their development. Even seasoned researchers continuously grapple with texts that require them to, for example, adapt a different reading strategy or make use of reference materials. Similarly, all students are on a reading development continuum as they commence and continue their journey through their undergraduate course. According to Alexander (2005:426), the use of oppositional terms such as 'struggling' versus 'successful' do not fit into the complexity of lifespan reading development. She suggests a range of profiles of more and less successful readers. From this perspective, all students have the ability to develop into readers who can cope with undergraduate reading demands; they just need to be provided for.

Alexander (2005:430) then defines reading as a complex process of growth and development within a certain domain. Her perspective is situated within New Literacy Studies (Gee 1990, 2003) that views literacy practices as socially constructed and embedded within a context. Alexander (2005) and Gee $(1990,2003)$ share similar views. According to Alexander, students need guidance from more knowledgeable people within a specific domain, while Gee notes that guidance should come from 'insiders' of a discourse community. From these findings, it can be deduced that reading development should be contextualised within specific disciplines. As such, reading should be developed under the thoughtful guidance of lecturers teaching disciplinary content as they are more knowledgeable about what exactly the students have to master. It seems that embedding academic literacy development, of which reading development forms part, 
within a discipline is an approach favoured by a number of researchers (Butler 2013; Hallett 2013; Jacobs 2007; Wingate 2007).

In order to juxtapose the reading skills approach against reading support and reading development within disciplinary contexts, another metaphor is useful. This metaphor is informed by Butler's (2013:76) reference to students as 'apprentices'. Students entering higher education want to learn a trade. Reading is a key they need to unlock the knowledge of the trade. Students are in different stages of their reading development. Some need little guidance and others need more. It is the responsibility of the trade masters, or the more knowledgeable others, to cultivate the right set of conditions to guide their apprentices as they develop their reading abilities. With expert guidance, students can become more knowledgeable to the extent that, like the trade masters, they have enough experience to further their own reading development. In the next section I present the theoretical framework of reading that I used as a point of departure for this empirical study.

\section{Theoretical framework of reading}

The applicable theoretical framework of reading was developed by the RAND Reading Study Group (2002). The purpose of this American study group, chaired by Catherine Snow, was to propose strategic guidelines to support the improvement of reading comprehension. This group define reading 'as the process of simultaneously extracting and constructing meaning through interaction and involvement with written language' (RAND Reading Study Group 2002:11). The study group came to the conclusion that reading can be conceptualised as a combination of variables, namely 'the reader who is doing the comprehending, the text that is to be comprehended and the activity in which comprehension is a part'. These three variables occur within a fourth variable, namely the socio-cultural context that influences and is influenced by the reader, the text and the activity (RAND Reading Study Group 2002:11). This framework clearly indicates that reading is the product of the interaction of variables and that each of these variables, both individually and in combination with each other, has implications for reading development (Woolley 2011:21). Each of the variables is briefly defined below, as these descriptions informed the planning of the data collection as well as the data analyses of this study.

\section{The reader (RAND Reading Study Group 2002):}

The reader brings to the act of reading his or her cognitive capabilities (attention, memory, critical analytic ability, inferencing, visualization); motivation (a purpose for reading, interest in the content, self-efficacy as a reader); knowledge (vocabulary and topic knowledge, linguistic and discourse knowledge, knowledge of comprehension strategies); and experiences. (p. xiii)

In this study, the reader is a first-year university student.
The text (RAND Reading Study Group 2002):

Texts can be difficult or easy, depending on factors inherent in the text (such as the text features), on the relationship between the text and the knowledge and abilities of the reader, and on the activities in which the reader is engaged. (p. 14)

In the context of this study, the texts were the prescribed academic textbooks students were expected to read.

The activity (RAND Reading Study Group 2002):

Reading does not occur in a vacuum. It is done for a purpose, to achieve some end. Activity refers to this dimension of reading. A reading activity involves one or more purposes, some operations to process the text at hand, and the consequences of performing the activity. (p. 15)

In an undergraduate higher education setting, reading activities take a variety of forms. These activities are always part of an assessment where, for example, the students write a class test on a chapter of their textbook that they had to read. In this study the term 'task' will be used as a collective term for all the different activities that students complete as part of assessment within the context of the different modules.

The socio-cultural context: The socio-cultural context refers to 'everything going on outside the classroom which might impact upon learning outcomes' (Haggis 2009:380). As the focus of this study is reading in a tertiary context, this statement can be rephrased as everything going on outside the lecture hall, which impacts on reading. The RAND Reading Study Group (2002:16) identified two main aspects: the environments in which individuals live and function, as well as the context of instruction. In the socio-cultural context of the first-year participants of this study, the transition from the school environment in which they functioned for 12 years to the new university environment in which they need to function is an important aspect of the environment within the socio-cultural context.

Lecturers are central to the context of instruction by orchestrating the teaching and learning activities of their modules. Furthermore, according to Bernstein (1999), each discipline has a certain 'gaze', that is, a certain way of viewing knowledge with a particular focus. Schoenbach et al. (2012:40) refer to the 'habits of mind' characteristic of a particular discipline. Lecturers themselves have these habits of mind with which they engage in their discipline. Lecturers also need to impart this 'gaze' to their students by making certain choices in the disciplinary instructional context (Bharuthram \& Clarence 2015:51). Lecturers usually have the freedom to choose the prescribed texts for their module and they also design the assessment tasks. As is clear from the theoretical framework, the text and the task influence the reading process and the lecturer can, to a large extent, choose and design these two variables. Thus, the lecturer plays an important role in reading development in the higher education context. In the next section I discuss the method and findings of this study. 


\section{Methodology Design}

At university the outcomes of reading are assessed in the form of tasks, but not reading itself (Bharuthram 2012:205; Pretorius 2002:170). Therefore, a qualitative method was used to uncover some of the problems lecturers and students were experiencing in terms of reading in the first year of study. The perceptions of students and lecturers on students' reading barriers were collected in semi-structured interviews held with lecturers and focus group interviews held with students. This qualitative study was part of my larger investigation of first-year students' reading comprehension and reading strategy use (Andrianatos 2018). The interview schedules of both the interviews and the focus group interviews were informed by the theoretical framework. As part of the larger study, the interviews and focus group interviews enabled me to compare students' and lecturers' perceptions about the students' reading abilities, the texts to be read and the tasks to be completed within a disciplinary context.

\section{Setting, population and participants}

A programme of study was randomly selected within the faculties of Humanities, Education, Natural Sciences, Health Sciences, Economic and Management Sciences, Law and Engineering. Thereafter lecturers responsible for the firstyear modules within the programme were invited to take part in the study. The first two lecturers who responded per faculty were selected $(N=14)$, and I refer to the two lecturers within a faculty as Lecturer A (LA) and Lecturer B (LB). I then visited a class of each of the lecturers and invited students to take part in a focus group interview at a specific time and place. The students who volunteered were chosen as participants $(N=56)$. Participants from seven faculties took part, namely Humanities $(N=8)$, Economic and Management Sciences $(N=12)$, Education Sciences $(N=7)$, Health Sciences $(N=10)$, Natural Sciences $(N=5), \operatorname{Law}(N=6)$ and Engineering $(N=8)$. The focus groups were held per faculty. I included participants from different faculties on the campus to get a more holistic picture of reading challenges as opposed to reading challenges experienced within one faculty.

\section{Measures, procedures and analyses}

The qualitative data collection methods were individual semi-structured interviews and focus group interviews. The interviews were conducted according to a semi-structured interview schedule based on the variables of the reading process according to the theoretical framework (RAND Reading Study Group 2002). This schedule consisted of four main discussion points, namely the perceived reading abilities of the students (reader), the influence of the prescribed academic texts of the module on reading (text), the influence of the tasks on reading (activities) as well as the influence of the lecturer and the specific requirements of the discipline with regard to reading (socio-cultural context). A semi-structured interview worked best in this study as it allowed me to clarify, probe and crosscheck responses. I also altered and rephrased questions according to the responses of the lecturer (Joubert, Hartell \& Lombard 2016:113). A focus group interview was held with a group of students from each of the seven faculties who were enrolled in the modules taught by the lecturers who were interviewed. The same interview schedule was used during the focus groups in order to gather data from the students' perspectives.

The data were analysed through the coding process of content analysis (Maree 2007:101). First, I read all the transcribed interviews and focus group interviews to gain a holistic view of the data. Stemming from the variables of the reading process as set out by the RAND Reading Study Group's theoretical framework (2002), the transcribed data were divided into sections: the reading abilities of students, the prescribed texts of the modules, the tasks, and comments relating to the socio-cultural contexts. These were the a priori codes. According to Maree (2007:107), this term refers to codes existing before data are analysed. After the data segments were divided, I made use of axial coding to uncover the barriers to reading within each of the codes.

\section{Results and discussion}

There are undoubtedly many barriers within the reading process. The results and discussion of the interviews and focus group interviews are presented per variable. Although these variables cannot be viewed in isolation from each other, their separation enabled me to analyse the different perspectives to be able to identify the perceived reading barriers.

\section{Barriers within the reader}

From the qualitative data analyses, I uncovered two barriers that can be situated within the reader, namely students' lacking reading abilities and their non-compliance with prescribed academic reading.

In general, the lecturers were of the opinion that students' reading abilities were lacking in terms of the reading demands of their modules. Some of their comments include:

'There are definitely many problems with reading, (and) understanding.' (LB, Education, female)

'I think less than $3 \%$ of my students truly engage with the prescribed reading material and can read with the needed insight.' (LB, Humanities, female)

Some of the students were also aware that they were struggling with reading:

'Because like, with the chapter ... when I read it, I get confused, so I just skim and scan, and when we do the actual chapter in class, that's when I literally understand.' (S4, Humanities, female)

Students experienced problems with understanding what they read, they are not complying with their prescribed 
reading, they 'take long' to read, and they struggle to understand 'difficult' words.

Their low reading abilities seemed to be one of the reasons why they did not read their prescribed textbooks. A cycle of non-compliance with prescribed academic reading emanated from the interviews. Firstly, students realise that their reading abilities are inadequate as they experience problems of comprehension as the following student comment indicates:

'The authors want to look smart. They wrote with their level, not our level.' (S7, Humanities, male)

Then, they do not allot the needed time to read the text with comprehension. It seemed that students could not sustain reading for longer periods and they might also have lacked the vocabulary needed to understand the textbook. This seemed to frustrate students:

'The textbook is so formal, so I do not have time to figure out what is going on. I rather study other modules where I understand everything.' (S3, Education, female)

As a result, students became dependent on the lecturer to explain what they were supposed to read:

'If it's important, the lecturer will explain it in class'.

Engineering, male)

From the lecturer's viewpoint, it is evident that students are non-compliant with the readings and therefore, because of the pressure to help students pass the module, the lecturer devoted class time to teach to the text:

'Students will be able to pass this module without using the textbook.' (LB, Engineering, female)

The students realise that the lecturer will review the needed sections of the textbook and so they are not forced to develop their reading in order to become better readers:

'We start with the lecturer's slides so we know what is going on. That way we won't look at unnecessary information in the textbook.' (S11, Economic and Management Sciences, male)

This cycle indicates that students themselves realise that they need to develop their reading abilities, but they would rather be non-compliant readers than take active steps to improve their reading abilities. The fact that lecturers take responsibility to 'teach' textbook content to students (e.g. identifying core aspects that could also be asked in tests etc.) reinforces students' non-compliance and their reading abilities are not improved. These findings on the negative cycle of non-compliance are supported by Ryan (cited in Hoeft 2012:2) and Bean (2001:134). Non-compliance and low reading ability definitely hinder students' reading development.

\section{Barriers within the text}

According to all 14 lecturers, the textbook they prescribed for their module was suitable for first-year students. It seemed as though the lecturers matched the outcomes of the module to the content of a textbook. As one lecturer justified:

'It is the only textbook available about the subject which is specifically suited for first-year students.' (LA, Natural Sciences, male)

The majority of students held a different opinion on their textbooks. They thought many of their textbooks were too 'difficult' and 'unnecessary'. This difference in opinion can be due to a 'mismatch' of students' reading abilities and the difficulty levels of the textbooks. The opinion of students that the textbooks were not suitable can also be traced back to the fact that reading was not essential in many of their modules. A student's frustration with realising that reading a textbook was, in fact, not necessary is evident from the following comment:

'The lecturer would say "prepare chapter 7 of the textbook" and he literally only uses a few points, and there I go and study the whole chapter, where I could have just like done something else.' (S2, Humanities, female)

The opinion of students that the textbooks were unsuitable can additionally be ascribed to the availability of other texts in the module. Students in different focus groups and two lecturers stated that it was not necessary for students to read the textbook with reference to certain modules. One lecturer said that she 'helped' the students by preparing notes which the students could photocopy. As a result, students had little or no use for the textbook.

Students depended on the lecturer to give the gist of the content and expected to be 'trained' for assessment and, in many cases, the lecturers met their expectations. This seems to nurture a non-reading culture where students can pass the module by only attending class and studying notes. In fact, from the analyses of all seven focus group interviews, it was clear that most students made use of notes as a primary text. These notes either took the form of 'handouts' from the lecturers' PowerPoint presentations, or were notes compiled by a peer. Furthermore, it became clear that selling and buying module notes was a practice among students. Students preferred these notes because information was summarised, to the point, and the key concepts were identified. These notes were, in many cases, the only text necessary to 'read' to complete tasks. The following comment made by a student indicates how the availability of notes influenced his perception of the necessity of reading:

'In the beginning of the year, I really studied from that textbook. Then when the test came, I did poorly. The next time I did not open the textbook, I just studied the notes. Now I've learnt my lesson.' (S1, Engineering, male)

The availability of notes partly influences students to adapt such a pragmatic approach to reading. Students run a 'costbenefit analysis' when it comes to prescribed academic reading as they determine the minimum reading investment that will help them reach at least the minimum task requirements (Schwartz n.d:1; Del Principe \& Ihara 2016:203). 
It seems that using information for different purposes is a characteristic of the current generation of students generally referred to as millennials. Morreale and Staley (2016:357) note that this generation of students 'are more likely to repurpose, recycle, and reuse information from others for their own creative purposes' than read seminal works and build their own knowledge. When other texts are available such as notes, and students can use the notes to complete the task, students see no reason to 'go to all the trouble' to read the textbook. It seemed as though students stopped looking for information when they found it in the slides. They generally do not read the textbook after they have studied the slides. This is definitely a barrier to their reading development.

\section{Barriers within the task}

From the data analysed it is clear that students and lecturers had different perceptions about reading as a requirement for task completion. All the lecturers remarked that students needed to read the prescribed texts to be able to complete the task. Different lecturers used the word 'force' as the following comments indicate:

'The purpose of the tests is to force students to work through the content.' (LB, Natural Sciences, male)

'The individual tests definitely force students to read the textbook.' (LA, Economic and Management Sciences, female)

The lecturers generally communicated the requirement of reading before starting the task, by providing students with relevant page numbers and informing them that reading is important. The link between the text and the task was clear to the lecturers, as they designed the tasks. For the students, however, the link between the text and the task was generally vague and in some cases absent. The barrier related to the task as variable seemed to be the format of the task.

To illustrate this barrier, I will discuss two examples. In one specific module, students had to give a presentation on a chapter in the textbook. The students worked together in groups of 10. According to the students, not all members took responsibility to read the chapter:

'I do not like the group work. Not everyone read the book. Just those who had to talk made sure they read the chapter.' (S2, Economic and Management Sciences, male)

In the second example, the students in one of the focus groups explained that one of their tasks was a tutorial class test. This test took place during a set time, where the students had to answer a set of questions using their textbook. Discussions among students were allowed and a lecturer was present. According to the students, the format of this tutorial test led to very little reading, but a lot of discussion, which they clearly preferred:

'I think it is much quicker when someone tells you something, than when you have to read a whole paragraph in detail. It takes long to read, reread and try to make sense of everything.' (S1, Natural Sciences, male)
During the focus group interviews students mentioned that they were content with 'getting by' (i.e. achieving a pass mark of $50 \%$ for a task). Students remarked that they would always try to find 'the easy way out' in terms of task completion, which would lead to at least $50 \%$. In other words, if the format of the task is group work where one can depend on another student to read the chapter, or a tutorial where peers and the lecturer are present to discuss difficulties, it is conceivable that for a goal of $50 \%$ task achievement, such tasks will lead to little or no reading development.

\section{Barriers within the socio-cultural context}

Within the socio-cultural context, the barriers of throughput pressure and lecturers' assumptions were uncovered. In the higher education environment, there is pressure to grant students access to university and make sure that they succeed. It seems as though lecturers experience pressure from institutional managers who are running a university like a business. More students equal more government subsidy and so throughput must be ensured. The following comments of two lecturers support this statement:

'I am of the opinion that lecturers do not pressure students to struggle with the textbook on their own, because all lecturers are under pressure to have a good throughput rate of students in their modules. As a result, the lecturers take on more and more responsibility and the students take on less and less. That negatively impacts the way students engage with their textbooks.' (LB, Natural Sciences, male)

'I also think that you have to find a balance between throughput figures in your module and knowledge that the students need to obtain. There is a lot of pressure not to have students fail your module, so it is not going to work if the material is too difficult. I try to achieve this balance with tutor classes and having the technical aspects of the essay count as much as the content of the essay. However a student can pass my module without doing a lot of reading, as long as they attend classes and do the needed assignments.' (LB, Humanities, female)

Throughput pressure is one of the barriers to reading as it seemed to increase lecturers' willingness to make their slides and notes available to their students. It also influenced the tasks they designed (including the format), as is clear from the comment that the technical elements of an essay count as much as the content, for example. When lecturers, as important role players within the socio-cultural context, make choices based on the pressure to help as many students as possible to pass their module, reading development can be hampered.

From the students' perspective it is understandable that they would not deem reading the textbook as an essential activity, as the lecturers provide summarised texts. It seemed as though this help is superficial. When lecturers make notes available that summarise a section of content, the students are deprived of a reading development opportunity to learn how one goes about making summaries from a section of a textbook. When students can attain $50 \%$ for a task by making sure the technical aspects are in place, for example, they are also in a way deprived of the responsibility to produce well-written content, 
like a well-structured argument, for example. This assumption also leads to a dependency on the lecturer as students do not learn how to be independent scholars - something they will need increasingly as they continue with further studies.

Lecturer's assumptions were another barrier that I uncovered within the socio-cultural context. Lecturers seemed to assume that their students can read independently and that students intuitively know how to 'use' scholarly discourse, in other words, what is expected in the discipline in terms of scholarly engagement. The following comments of different lecturers illustrate these assumptions:

'I cannot understand why students do not do well in this module. It is very straightforward. The students have to read, remember and give the information in a test.' (LA, Economic and Management Sciences, female)

'They should have read something before they enter my class.' (LA, Law, female)

'I think the vocabulary and language (of the textbook) are suitable for first-year students. I do not think it is difficult.' (LA, Natural Sciences, female)

From the data analyses of the focus groups, it seemed that many of the students are not independent readers and struggle with scholarly engagement:

'I just look at the [text]book and I get drained.' (S8, Humanities, female)

'With one of my modules I read and read, and I still don't understand.' (S1, Education, female)

I think the textbook of this one module is way too complicated.' (S5, Education, female)

'The textbook compresses the information in such a way that it is there, but it is not there.' (S3, Economic and Management Sciences, male)

'It [reading the textbook and completing a certain task] is nothing like that which we did at school. We do not understand it well.' (S4, Natural Sciences, male)

Because of the assumption that students should be prepared for scholarly engagement and reading, the interviewed lecturers did not seem to make any provision for students' reading development. Students seemed discouraged about their own reading practices within the context of their modules. They seem to realise that their reading abilities are not meeting the lecturers' expectations, but they are unsure how this can be remedied. One student remarked that he did not fare well in a task and that in future he is going to read the notes 'better'. This is ironic because the student failed to realise the core issue: he was not reading the textbook, but rather someone else's summarised version of it. I am of the opinion that lecturers' assumptions create a distance between the lecturers and the reading development needs of the students.

\section{The reading mechanism}

As the final part of the results, I present a visual representation as a summary of the discussed reading barriers (see Figure 1).

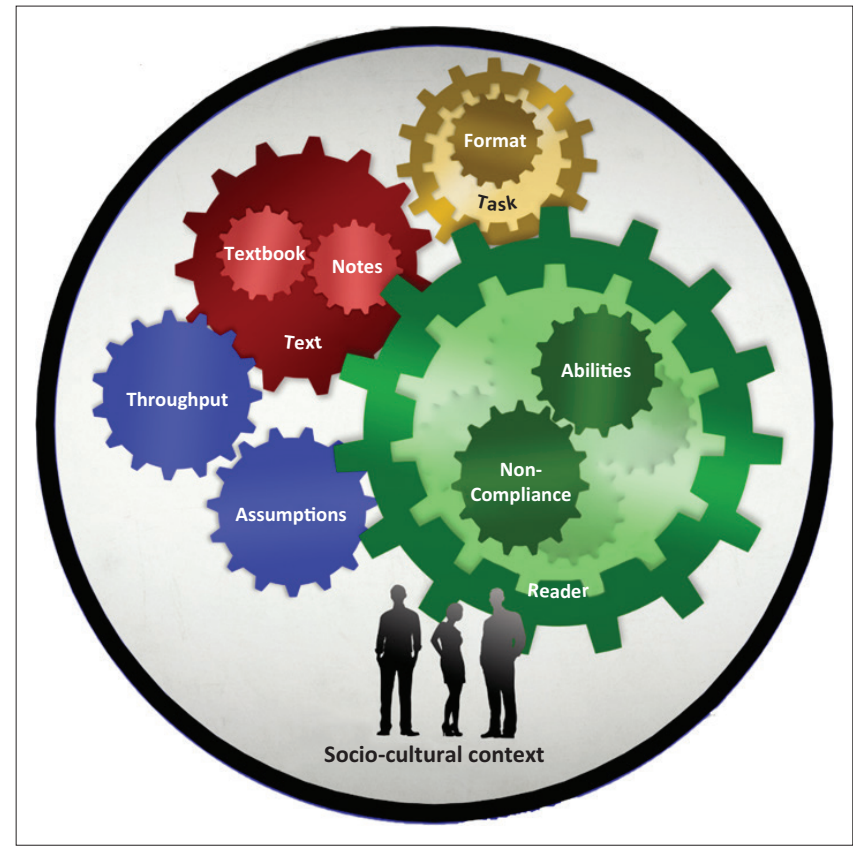

FIGURE 1: The reading mechanism: Barriers to reading within the reader, the text, the task and the socio-cultural context.

This representation was developed through a combination of theory and the findings of this qualitative study. As stated, reading is the product of the interaction of variables (RAND Reading Study Group 2012). Based on this view of the reading process, I present the interrelated variables as cogs in a mechanism. In this visual representation, the barriers are presented as smaller 'broken' cogs that obstruct the functioning of the bigger cogs and thus also the functioning of the reading mechanism. This metaphor indicates that the uncovered barriers hamper students' reading development.

\section{Ethical consideration}

The setting of the study was the Potchefstroom campus of the NWU. The study population was first-year students and lecturers responsible for first-year modules. As the highest attrition occurs in the first year of study (Scott et al. 2007), first-year students and their lecturers were chosen as participants. All participants volunteered to take part in this study and approval was obtained from the university's ethics committee.

\section{Conclusion}

Higher education institutions in South Africa have a responsibility to help the students who gain access to a tertiary education to succeed. From a lifespan developmental perspective on reading, all students can develop into competent readers; they just need to be provided for (Alexander 2005). If reading is understood as the interaction between the variables of the reader, text and task within a socio-cultural context (RAND Reading Study Group 2002:11), generic reading support cannot be the answer to our students' reading challenges. A handful of academic literacy practitioners or support staff cannot effectively help undergraduates from different faculties to, for example, 
read their chemistry textbooks or court cases. The lecturer teaching academic content is a critical role player in students' reading development. As is clear from the visual representation in Figure 1, the lecturer usually decides on the task (design and format) and the text (including whether or not to make notes available). These choices influence the reading process. Although reading abilities and noncompliance are barriers within the reader, we cannot place the responsibility for reading development squarely on the shoulders of our students. They do not have a reading 'illness' that can be 'cured'. In my opinion they are new apprentices in need of guidance from an insider within a discourse community (Gee 2003). In my mind, there is no better insider than the lecturer.

It is a fact that the South African school system is not preparing our students optimally for university. The academic literacy and support departments can definitely contribute to improve students' academic literacy, of which reading is an integral part. However, other role players like lecturers, faculty boards and institutional management should move beyond blame shifting to accountability in terms of students' reading development. Van de Poel and Van Dyk (2014:172) refer to a collaborative approach. Lecturers are appointed at universities because of their expertise in a certain discipline. As lecturers, the teaching and learning policy of the university states that they should guide students to reach module outcomes 'through active learning activities suitable to the level of autonomy expected at a certain level' (North-West University 2011:1). Disciplinary experts do not necessarily have knowledge of what constitutes such a suitable activity and might therefore be unable to design activities that closely link the text and the task so as to aid students' reading development. The teaching and learning support structure of a university includes individuals who are skilled in developing active learning activities and have knowledge of the reading process, but they lack disciplinary knowledge. The Education Sciences faculty can also contribute in terms of how reading support should feature within curriculum design. Such a team effort can possibly result in synergy between disciplines, the fostering of a relationship between role players who take responsibility and students who have the needed opportunity to develop their reading abilities.

The aim of this article was to uncover reading barriers that students and lecturers perceive so that role players can gain insight into the reading support needed at higher education institutions. One limitation of the study is that the uncovered barriers might only exist for the specific context in which the study took place. It will be naive to think that addressing each separate barrier will help students to read better. It would not be theoretically sound to take the reading 'mechanism' apart and attempt to 'fix' the separate cogs. All role players have to understand that reading is an interconnected and complex process. Role players, especially lecturers, should take cognisance of some of the reading barriers that lecturers unintentionally cause and students unknowingly experience, and how the variables of the reader, the text and the task influence each other within the context of a discipline. In this way, we can move a step closer towards collaboratively planning the developmental reading opportunities our students need as opposed to the limited generic reading support that is presently offered.

\section{Acknowledgements}

The author would like to express her gratitude to Prof. Carisma Nel for her expert guidance in this research project. Also thank you to all the lecturers and students who participated and were willing to share their experiences.

\section{Competing interests}

I declare that I have no financial or personal relationships that may have inappropriately influenced me in writing this article.

\section{Author's contributions}

I declare that I am the sole author of this research article.

\section{Funding information}

This research received no specific grant from any funding agency in the public, commercial, or not-for-profit sectors.

\section{Data availability statement}

Data sharing is not applicable to this article as no new data were created or analysed in this study.

\section{Disclaimer}

The views and opinions expressed in this article are those of the author and do not necessarily reflect the official policy or position of any affiliated agency of the author.

\section{References}

Alexander, P.A., 2005, 'The path to competence: A lifespan developmental perspective on reading', Journal of Literacy Research 37(4), 413-436. https://doi.org/10.1207/ s15548430j|r3704_1

Andrianatos, K., 2018, 'First year university students' reading strategies and comprehension: Implications for academic reading support', PhD thesis, Faculty of Education Sciences, North-West University.

Archer, A., 2006, 'A multimodal approach to academic "literacies": Problematising the visual/verbal divide', Language and Education 20(6), 449-462. https://doi. org/10.2167/le677.0

Bean, J.C., 2001, Engaging ideas: The professor's guide to integrating writing, critical thinking, and active learning in the classroom, Jossey-Bass, San Francisco, CA.

Berndt, A., Petzer, D.J. \& Wayland, J.P., 2014, 'Comprehension of marketing research texts among South African students: An investigation', South African Journal of Higher Education 28(1), 28-44. https://doi.org/10.20853/28-1-321

Bernstein, B., 1999, 'Vertical and horizontal discourse: An essay', British Journal of Sociology of Education 20(2), 157-173. https://doi.org/10.1080/ 01425699995380

Bharuthram, S., 2012, 'Making a case for the teaching of reading across the curriculum in higher education', South African Journal of Education 32(2), 205-214. https:// doi.org/10.15700/saje.v32n2a557

Bharuthram, S. \& Clarence, S., 2015, 'Teaching academic reading as a disciplinary knowledge practice in higher education', South African Journal of Higher Education 29(2), 42-55

Boakye, N., Sommerville, J. \& Debusho, L., 2014, 'The relationship between socioaffective factors and reading proficiency: Implications for tertiary reading instruction', Journal for Language Teaching 48(1), 173-213. https://doi.org/ 10.4314/jlt.v48i1.9 
Butler, G., 2013, 'Discipline-specific versus generic academic literacy intervention for university education: An issue of impact?', Journal for Language Teaching 47(2), 71-87. https://doi.org/10.4314/jlt.v47i2.4

Del Principe, A. \& Ihara, R., 2016, “I bought the book and I didn't need it": What reading looks like at an urban community college', Teaching English in the Two Year College 43(3), 229-244.

Gee, J.P., 1990, Social linguistics and literacies: Ideologies in discourses, Falmer, London.

Gee, J.P., 2003, What video games have to teach us about learning and literacy, Palgrave Macmillan, New York.

Haggis, T., 2009, 'What have we been thinking of? A critical overview of 40 years of student learning research in higher education', Studies in Higher Education 34(4), 377-390. https://doi.org/10.1080/03075070902771903

Hallett, F., 2013, 'Study support and the development of academic literacy in higher education: A phenomenographic analysis', Teaching in Higher Education 18(5), 518-530. https://doi.org/10.1080/13562517.2012.752725

Hoeft, M.E., 2012, 'Why university students don't read: What professors can do to increase compliance', International Journal for the Scholarship of Teaching and Learning 6(2), 1-19. https://doi.org/10.20429/ijsotl.2012.060212

Howard, P.J., Gorzycki, M., Desa, G. \& Allen, D.D., 2018, 'Academic reading: Comparing students' and faculty perceptions of its value, practice, and pedagogy', Journal of College Reading and Learning 48(3), 189-209. https://doi.org/10.1080/1079019 5.2018 .1472942

Jacobs, C., 2007, 'Towards a critical understanding of the teaching of discipline-specific academic literacies: Making the tacit explicit', Journal of Education 41(1), 59-81.

Joubert, I., Hartell, C. \& Lombard, K. (eds.), 2016, Navorsing: 'n gids vir die beginner navorser, Van Schaik, Pretoria.

MacMillan, M., 2014, 'Student connections with academic texts: A phenomenographic study of reading', Teaching in Higher Education 19(8), 943-954. https://doi.org/10 .1080/13562517.2014.934345

Maree, K., 2007, First steps in research, Van Schaik, Pretoria.

McLoughlin, K. \& Dwolatzky, B., 2014, 'The information gap in higher education in South Africa', South African Journal of Higher Education 28(2), 584-604. https:// doi.org/10.20853/28-2-344

Morreale, S.P. \& Staley, C.M., 2016, 'Millennials, teaching and learning, and the elephant in the college classroom', Communication Education 65(3), 370-373. https://doi.org/10.1080/03634523.2016.1177842

Nel, C., Dreyer, C. \& Klopper, M., 2004, 'An analysis of reading profiles of first-year students at Potchefstroom University: A cross-sectional study and a case study', South African Journal of Education 24(1), 95-103.
Niven, P.M., 2005, 'Exploring first year students' and their lecturers' constructions of what it means to read in a humanities discipline: A conflict of frames?', South African Journal of Higher Education 19(4), 777-789. https://doi.org/ 10.4314/sajhe.v19i4.25667

North-West University, 2011, Teaching and learning policy, viewed 22 November 2017, from http://www.nwu.ac.za/sites/www.nwu.ac.za/files/files/i-governancemanagement/policy/8P-8_\%20TLA\%20policy_e.pdf.

Pretorius, E.J., 2002, 'Reading ability and academic performance in South Africa: Are we fiddling while Rome is burning', Language Matters 9(33), 169-196. https://doi. org/10.1080/10228190208566183

Pretorius, E.J., 2005, 'What do students do when they read to learn? Lessons from five case studies', South African Journal of Higher Education 19(4), 790-812. https:// doi.org/10.4314/sajhe.v19i4.25668

RAND Reading Study Group, 2002, Reading for understanding: Toward an R\&D program in reading comprehension, RAND, Santa Monica, CA.

Schoenbach, R., Greenleaf, C. \& Murphy, L., 2012, Reading for understanding: How reading apprenticeship improves disciplinary learning in secondary and college classrooms, John Wiley, San Francisco, CA.

Schwartz, M., n.d., The learning and teaching office. Getting students to do their assigned readings, viewed 15 November 2017, from https://www.ryerson.ca/ content/dam/lt/resources/handouts/student_reading.pdf.

Scott, l., Yeld, N. \& Hendry, J., 2007, Higher education monitor: A case for improving teaching and learning in South African higher education, Council on Higher Education, Pretoria.

Styan, J.B., 2014, 'The state of SA's tertiary education', Finweek 6(19), 10-15.

Taraban, R., Rynearson, K. \& Kerr, M., 2000, 'College students' academic performance and self-reports of comprehension strategy use', Reading Psychology 21(4), 283-308. https://doi.org/10.1080/027027100750061930

Van de Poel, K. \& Van Dyk, T., 2014, 'Discipline-specific academic literacy and academic integration', in R. Wilkinson \& M.L. Walsh (eds.), Integrating content and language in higher education: From theory to practice, pp. 162-179, Peter Lang, Frankfurt am Main.

Van Dyk, T., Van de Poel, K. \& Van der Slik, F., 2013, 'Reading ability and academic acculturation: The case of South African students entering higher education', Stellenbosch Papers in Linguistics Plus 42(1), 353-369. https://doi. org/10.5842/42-0-146

Wingate, U., 2007, 'A framework for transition: Supporting "learning to learn" in higher education', Higher Education Quarterly 61(3), 391-405. https://doi. org/10.1111/j.1468-2273.2007.00361.x

Woolley, G., 2011, Reading comprehension: Assisting children with learning difficulties, Springer, Dordrecht. https://doi.org/10.1007/978-94-007-1174-7_1 